\title{
A cultura na cidade
}

\section{RICARDO OHTAKE ${ }^{I}$}

A

S CIDADES crescem de acordo com a sua cultura e de seus habitantes. Embora seja uma afirmação óbvia, é sempre importante lembrar a forma extremamente clara que as cidades adquirem no decorrer de suas histórias, as diferentes bases em que elas estão fundadas, seus costumes, porque é com elas que se erguem os conceitos que estão impregnados em seus movimentos.

As cidades brasileiras tiveram, até o final do século XIX, os seus centros históricos com traçado marcado por ruas estreitas, com pouco mais de 10 metros, edificações que chegavam aos limites das ruas, uniam paredes com outros limites laterais e tinham espaços abertos só no fundo, por onde ninguém passava.

O terreno de uma edificação era retangular e esse costume se mantém até os terrenos loteados hoje. Na metade do século XX, com o desenvolvimento das técnicas de construção, foi possível desligar a edificação do chão, um dos adventos modernos que possibilitariam finalmente modificar a estrutura dos espaços públicos estendendo as ruas aos espaços térreos dos lotes.

Os térreos livres modernos, com maciça aplicação nas décadas de 1950 e 1960 no Brasil, fizeram-se presentes desde habitações unifamiliares como o projeto da Casa de Vidro de Bo Bardi a extensos programas, como um dos primeiros exemplos as superquadras previstas na Brasília de Oscar Niemeyer e Lucio Costa. Porém, tal iniciativa tornou-se oportunidade perdida, uma vez que o que vemos hoje são poucos edifícios abrindo seus espaços térreos para a circulação de pedestres, restringindo-se àqueles que neles habitam ou trabalham. $\mathrm{O}$ temor da falta de segurança e a necessidade de demarcar a posse da propriedade tornaram os terrenos fechados em si mesmos.

Se, por um lado, pouco dessas iniciativas se abriram para o entorno e tornaram-se permeáveis aos seus habitantes, por outro, no que tange ao desenho, o grande pecado foi que conjuntos habitacionais recorreram a um mesmo módulo padrão repetido dezenas e centenas de vezes, dentro de lotes iguais, destituindo da cidade sua interessante volumetria irregular e uma parcela de sua complexidade. Talvez seja possível dizer depois de inúmeras experiências que, embora se verifique a racionalidade da construção e seu menor custo, isso se dá mediante a pobreza do desenho repetitivo.

Esses diferentes fatores somados resultam em espaços de convivência escassos, com uma grande quantidade de construções reduzidas a ambientes pouco convidativos ao encontro com colegas, vizinhos e desconhecidos.

Em um panorama geral, o que parece mais evidente, seja na rua do século XIX, seja no prédio e residência do século XX, é que o espaço coletivo é muitas 
vezes deixado em segundo plano ou menos resolvido. O espaço coletivo é relativizado pelos números de participantes dos espaços, tanto que numa residência é só uma família, com duas, três, cinco, oito pessoas no máximo, onde a convivência desses membros já torna o espaço coletivo. No interior de um prédio residencial ou comercial, o espaço coletivo pode ser de duas a dezenas de pessoas.

Um importante estudo acerca do tema trata-se da pesquisa do arquiteto e professor Julio Katinsky, realizada em 2011, abordando uma breve genealogia dos espaços de convivência na formação das cidades brasileiras. A pesquisa resultou em exposição curada por Katinsky (2011), no Instituto Tomie Ohtake, em que o define espaço de convivência com base no livro Casa grande e senzala (1934) publicado por Gilberto Freyre (2005). A releitura de Katinsky retoma o conceito freyriano como sendo o espaço entre as duas construções, o que é extremamente explicativo, pois a convivência máxima que se pode dar é entre as duas classes sociais existentes nesse conjunto e só acontecerá à medida que a divisão das estruturas sociais e econômicas desses grupos se abrir. Gilberto Freyre e Katinsky estão separados por mais de 80 anos e a sociedade avançou, mas não o desejado, ou seja, o espaço de convivência continua a ser mais de um lado separado do outro, mesmo com a abertura de muitas brechas.

O espirito coletivo, olhar o outro, nós são atitudes que fazem parte da vida urbana, ou seja, não ter mais a vida isolada, a vida rural, mas que também já ultrapassou o medievo imaginando povoados de países muçulmanos que se mantêm ainda hoje, cortiços das zonas periféricas e antigas das cidades brasileiras, e de muitos outros países pobres, todas essas formas de moradias, em caráter definitivo.

As moradias provisórias, sejam em favelas, sejam em palafitas, foram se consolidando no Brasil em não muito mais do que um século, ao ponto de, apesar de toda a precariedade, ter dono, aluguel e os organizadores da ordem interna. A complexidade dessas organizações coletivas cresce exponencialmente e é tema de discussão e pesquisa de sociólogos, sendo também retratadas cotidianamente em novelas de televisão para milhões de pessoas.

As regiões sob a legislação urbana ou sob a força de alguns de seus moradores (os chefões) obedecem ao mercado, capitalista, embora nem sempre, ou poucas vezes, de maneira legalizada. Situação em que a ordem jurídica é pouco respeitada, como, aliás, ocorre em muitas outras instâncias do país.

Como então organizar uma cidade nessas condições? Embora saibamos dessa dificuldade, a Universidade poderia ser uma ilha em que essa situação seja discutida e organizada a sua praticização. Afinal, é aproveitando as brechas permitidas pelo sistema urbano que serão organizadas as interferências.

As diretrizes de desenvolvimento são traçadas pelas vias rodoviárias, acompanhadas de outras medidas que permitam colocar habitação e os seus equipamentos (como comércio e serviços, educação, saúde, esportes, diversão) juntamente com trabalho (escritórios, pequenas indústrias, sedes de grandes 
indústrias, áreas verdes e alguns grandes equipamentos urbanos), delimitando pequenas centralidades de bairro. Esses polos de centralidade se definiriam, por exemplo, delimitando um espaço de 500 metros de lado, circundado por avenidas e estradas radiais.

Essa operação e todos os devidos reparos devem ser conduzidos por eficientes e apaixonados arquitetos, urbanistas, sanitaristas, economistas, excelentes administradores públicos, advogados, estudiosos da sociedade, esclarecidos, experientes e corajosos profissionais que representem o conhecimento universal e universitário, condignamente.

O espaço físico da cidade é uma base onde os habitantes dela vão desenvolver todo o seu potencial humano. Existe nesse potencial o que individualmente cada um pode realizar, mas a própria existência da cidade traz todos a terem uma vida em comum, o que a torna extremamente interessante.

A filosofia, as ciências, as técnicas permitem a convivência e a divisão por classes, raças e culturas, ou, por outras diferenças, acolhem diferentes entendimentos do mundo.

No entanto, os entendimentos são mais ou menos poderosos, criando hoje em dia não mais situação e oposição, mas incluídos e excluídos, que ficam claramente observados nas cidades brasileiras.

O planejamento urbano deve levar em conta questões que vão proporcionar à população uma vida digna, mas o planejamento urbano, instrumento do Estado, é pouco realizado para a população já que se mantém na concepção e não na execução - o planejamento acaba sendo mais um exercício de mapeamento em papel pintado destituído de compromisso entre projeto e realidade. E que bom seria se a minha querida Faculdade de Arquitetura e Urbanismo da Universidade de São Paulo (FAU-USP) fosse verdadeira agente de um desenvolvimento urbano para toda a população.

É nesse sentido que chamamos algumas das esclarecidas pessoas dotadas de clarividência para dizer o que fazer para realizar uma cidade com belo desenho urbano, com população orgulhosa de sua cidade, neste convite que nos foi feito pelo editor de Estudos Avançados, o professor Alfredo Bosi.

Com base na reflexão acerca do urbanismo e da cidade contemporâneos, os convites se deram a profissionais das mais diferentes áreas. Partiu-se do pressuposto que a discussão e pesquisa sobre nossas cidades poderia e deveria permear-se pelo contato entre urbanismo e diferentes campos do conhecimento. É a partir dessa convergência que procuramos explorar com os ensaios que se seguem possibilidades de reflexão históricas e críticas acerca dos campos urbanismo, da arte e da cultura. Os convites se baseiam em alguns eixos temáticos desenhados previamente como objetivo deste dossiê.

O primeiro desses eixos, trata da "Construção da cidade", visando abordar o projeto da cidade a partir de seu crescimento e evolução e lidando com as idiossincrasias e entraves. Esse núcleo visa abordar o planejamento urbano a 
partir do projeto e da análise do espaço construído. Convidamos Daniel Corsi, arquiteto formado na Universidade Presbiteriana Mackenzie, na qual conclui seu mestrado e sua graduação. Corsi tem importante atuação como professor em escolas de arquitetura, mas tem no exercício do projeto uma das suas exímias atividades com rica participação em concursos e projetos de edificações.

O segundo eixo temático busca tratar da "Dimensão histórica da ação humana na cidade". Nesse eixo, a produção da cidade é analisada a partir de transformações propiciadas não somente por projetos de intervenção, mas por dinâmicas sociais e conflitos. A dimensão histórica de análise das cidades ganha subsídio por intermédio de leituras que aproximam antropologia e projeto urbano. Para abordar essa relação de maneira brilhante e precisa, convidamos a historiadora e antropóloga Lilia Moritz Schwarcz, professora titular, livre-docente e doutora em antropologia social pela Universidade de São Paulo. Atualmente é curadora adjunta do Masp e tem importante atuação com curadoria e pesquisas em exposições que aproximam antropologia, arte e contextos sociais, como Um olhar sobre o Brasil (2012, com Boris Kossoy) e Histórias mestiças (2014, com Adriano Pedrosa), ambas realizadas no Instituto Tomie Ohtake. Publicou recentemente Lima Barreto: triste visionário (2017), vasta biografia sobre o escritor carioca.

O terceiro eixo temático trata "A cidade como síntese do conhecimento" abordando diferentes modos de leitura, análise e intervenção do urbano sob a óptica de outros campos disciplinares. A ênfase desse eixo aponta aproximações entre a produção artística e a crítica de arte como subsídios a pensar a cidade, não só em termos históricos, como atuais. Convidamos para essa análise Priscyla Gomes, mestre em Arquitetura e Urbanismo pela Faculdade de Arquitetura e Urbanismo da Universidade de São Paulo. Atualmente, Priscyla é curadora associada do Instituto Tomie Ohtake e pesquisadora dos campos de arquitetura, artes e design.

O quarto e último eixo do dossiê aborda providencialmente "O futuro da cidade brasileira" trazendo um ensaio acerca das potencialidades em intervir e pensar a problemática da cidade sob a óptica da produção artística.

A partir da aproximação entre arte e espaço urbano, a análise traz subsídios para pensar transformações no tecido urbano potencializadas por um imbrincado diálogo entre arte, arquitetura, geografia e gestão cultural. A escolha do convidado, novamente, não poderia ser mais adequada e oportuna: Nelson Brissac Peixoto é filósofo, mestre em Filosofia pela Pontifícia Universidade Católica de São Paulo e doutor pela Universidade de Paris I - Sorbonne. Nas últimas décadas, Brissac tem trabalhado em cinema, participado de projetos de arte, além de ser idealizador e curador do projeto Arte/Cidade desde 1994. O projeto conta com a participação de artistas visuais, fotógrafos, cineastas, coreógrafos, diretores teatrais, engenheiros, arquitetos, com os quais Brissac estabelece um intenso diálogo e parceria. O projeto, que foi ganhando escala e complexidade com o 
passar dos anos, integrou-se à cidade englobando vastas áreas, até bairros inteiros. Agora, em sua quinta edição, Brissac desenvolve ligações entre SP-Santos e o Vale do Ruhr na Alemanha, em parceria com o Instituto Tomie Ohtake.

Os convites e perfis dos convidados trazem diferentes gerações e campos de atuação buscando expandir as discussões acerca do urbanismo e da cultura. Privilegiou-se a escolha de nomes que trouxessem não somente sua vasta contribuição como pesquisadores nos referidos campos, mas que tivessem uma engajada atuação como arquitetos, curadores, gestores e professores. Uma forma de enfatizar a produção de conhecimento como vivência também junto à prática de projeto e atuação institucional, buscando potentes interlocutores à discussão urgente e muito bem-vinda sobre os futuros caminhos e desafios das nossas cidades.

\section{Referências}

FREYRE, G. Casa grande es senzala. 50.ed. Rio de Janeiro: Global Editora, 2005.

KATINSKY, J. Arquitetura brasileira: o coração da cidade - A invenção dos espaços de convivência. São Paulo: Instituto Tomie Ohtake, 2011.

RESUMO - Como articular diferentes campos de conhecimentos para responder aos desafios contemporâneos das cidades brasileiros? Sob o viés histórico e social de crescimento e formação das cidades no Brasil mapeiam-se possibilidades, desenhos e interlocuções profícuos aos desafios lançados.

PALAVRAS-CHAVE: Arquitetura, Arte, Cidade, Cultura, Desenho, Espaço, Gestão cultural, Instituição, Planejamento, Urbanismo.

ABSTRACT - How does one articulate different fields of knowledge to respond to the contemporary challenges of Brazilian cities? From a historical and social viewpoint of growth and formation of cities in Brazil, fruitful possibilities, designs and dialogues emerge to these challenges.

KETWORDS: Architecture, Art, City, Culture, Design, Space, Cultural management, Institution, Planning, Urbanism.

Ricardo Ohtake dirige o Instituto Tomie Ohtake desde sua criação, em 2001. Foi secretário de Estado da Cultura de São Paulo, dirigiu o Centro Cultural São Paulo, o Museu da Imagem e do Som (MIS) e a Cinemateca Brasileira. Formou-se em arquitetura pela FAU-USP e trabalhou em importantes questões urbanas, principalmente quando foi Secretário do Verde e Meio Ambiente do Município de São Paulo. Foi membro do Conselho Deliberativo do Instituto de Estudos Avançados da USP entre 2015 e 2016 e é o atual titular da Cátedra Olavo Setúbal de Arte, Cultura e Ciência.

@ - ricardo.ohtake@institutotomieohtake.org.br

Recebido em 26.9.2017 e aceito em. 8.10.2017.

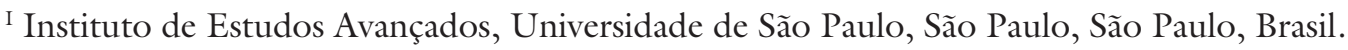

